\title{
Ensembl variation resources
}

\author{
Yuan Chen+1, Fiona Cunningham¹, Daniel Rios', William M McLaren¹, James Smith², Bethan Pritchard², \\ Giulietta M Spudich', Simon Brent², Eugene Kulesha1, Pablo Marin-Garcia², Damian Smedley¹, Ewan Birney and \\ Paul Flicek ${ }^{* 1,2}$
}

\begin{abstract}
Background: The maturing field of genomics is rapidly increasing the number of sequenced genomes and producing more information from those previously sequenced. Much of this additional information is variation data derived from sampling multiple individuals of a given species with the goal of discovering new variants and characterising the population frequencies of the variants that are already known. These data have immense value for many studies, including those designed to understand evolution and connect genotype to phenotype. Maximising the utility of the data requires that it be stored in an accessible manner that facilitates the integration of variation data with other genome resources such as gene annotation and comparative genomics.

Description: The Ensembl project provides comprehensive and integrated variation resources for a wide variety of chordate genomes. This paper provides a detailed description of the sources of data and the methods for creating the Ensembl variation databases. It also explores the utility of the information by explaining the range of query options available, from using interactive web displays, to online data mining tools and connecting directly to the data servers programmatically. It gives a good overview of the variation resources and future plans for expanding the variation data within Ensembl.

Conclusions: Variation data is an important key to understanding the functional and phenotypic differences between individuals. The development of new sequencing and genotyping technologies is greatly increasing the amount of variation data known for almost all genomes. The Ensembl variation resources are integrated into the Ensembl genome browser and provide a comprehensive way to access this data in the context of a widely used genome bioinformatics system. All Ensembl data is freely available at http://www.ensembl.org and from the public MySQL database server at ensembldb.ensembl.org.
\end{abstract}

\section{Background}

The amount of publicly available biological sequence data has been increasing exponentially over the last decade. In addition to the many reference genome sequences now available, variation data is being produced in significant quantities. These data fundamentally seek to extend our knowledge of the genome sequence from the concept of a single "reference" genome sequence, representing a single individual, to a more comprehensive understanding of the genomic diversity of entire species.

Today most variation data is produced in the context of large-scale genotyping assays or resequencing projects

\footnotetext{
*Correspondence: flicek@ebi.ac.uk

1 European Bioinformatics Institute, Wellcome Trust Genome Campus, Hinxton, Cambridge, CB10 1SD, UK

+ Contributed equally

Full list of author information is available at the end of the article
}

which focus either on the whole genome or selected functional regions of the genome such as protein coding regions, regulatory regions or sites of known disease mutations. One of the larger resources includes a comprehensive haplotype map of the human genome created by the International HapMap Project, based on DNA from 270 individuals from four populations [1]. The HapMap Project used array-based genotyping to assess markers with minor allele frequency (MAF) of greater than approximately $5 \%$. Following on from this project, many of these same HapMap individuals are included with others in the 1000 Genomes Project [2], which seeks to assay variant sites including those with much lower MAFs. Previous efforts to map variation in other species include strain specific mouse resequencing [3,4], a haplotype mapping in rat [5], as well as data mining of public domain resources such as NCBI's dbSNP [6]. Whole 
genome shotgun sequencing can be used for reliable variant discovery in a single sequenced individual by comparing the sequencing reads to the final consensus assembly as done with platypus [7]. When a reference assembly exists, it is more efficient to compare the sequenced individual to that assembly as this technique facilitates the discovery of both heterozygous variants within the individual and variants between the individual and the reference. Reference based variation discovery has been used for several species including human $[8,9]$, mouse [4], rat [5], and chicken [10].

These huge datasets including variation data are often available from the original sources in a variety of formats requiring the development of various methods to integrate, archive and display these data in a consistent fashion. Ensembl [11], University of California at Santa Cruz (UCSC) $[12,13]$ and the National Center for Biotechnology Information (NCBI) [14] have expertise in the storage and manipulation of biological data and have developed genome browsers and other methods to archive and display these data alongside their other large scale data resources. The variation data stored in Ensembl are discussed here.

\section{Ensembl}

The Ensembl project is a comprehensive bioinformatics resource for chordate genomes. Thousands of researchers from around the world access Ensembl data every day through the various portals provided by the project including the web interface at http://www.ensembl. org[15], the Ensembl API [16], and Ensembl BioMart [17]. In addition to the chordate genomes, selected model organisms (D. melanogaster, C. elegans, S. cerevisiae) are included to facilitate comparative analysis. More comparative analysis is available using species supported by Ensembl Genomes project, a sister project extending Ensembl analysis across a larger taxonomic space [18].

Ensembl is updated approximately every two months with newly sequenced genomes and newly available or processed data for existing genomes. The project specialises in integrating large-scale data from many different sources in a variety of formats with a high-quality annotation of the genome and gene set. In addition to comparative and functional genomics data resources, Ensembl provides variation data for a number of supported species.

Each year, Ensembl publishes a general update of all the project's resources $[11,19,20]$. In contrast to these highlevel overviews, this is a more in-depth report specifically on the growing number of variation resources available within Ensembl. It describes, in detail, how data is extracted and combined from primary sources such as the Ensembl Trace Archive [21] and NCBI's dbSNP [6], how it is generated using data from resequencing infor- mation, how it is visualised and how to obtain the data via the website.

\section{Construction and Content}

Ensembl produces variation databases for a subset of the genomes available in Ensembl (first two columns of Table 1). This allows integration and easy access to variation data from multiple sources as well as the effects of sequence variation on the genes. The databases incorporate four types of data: a complete polymorphism catalogue, genotype data from specific projects, phenotype data and selected resequencing data. The primary source of polymorphism and genotype data for SNPs and in-dels is from dbSNP, the major public archive of variation data, which is integrated with data from other sources as described below. Structural variants are imported from DGVa [22] and for some species, additional variants are generated from uniform processing and variation discovery using sequencing reads from the Ensembl Trace Archive (see column 4 of Table 1). Phenotype data comes from both a manually curated resource and a public archive, as explained below. Finally a series of qualitycontrol stages are implemented as described below. In this way, Ensembl can begin to provide a comprehensive picture of variations, their effects, and their context.

The Ensembl variation resources are updated when a new genome assembly is released, a new set of gene annotations is available or revised, an external data source such as dbSNP at the NCBI is updated or a major new data collection becomes available.

Variation data is stored in a structured MySQL database. A companion paper describes the underlying database technology that is used to efficiently store and manage this data and the associated Application Program Interface (API) for programmatic access to the data [23].

\section{Data Sources}

\section{Importing variation data from dbSNP}

The bulk of the SNP and in-del variation data in Ensembl is an imported dataset from dbSNP. This information is selected from dbSNP's largest tables. Table 2 describes the relationship between the dbSNP database tables and the corresponding Ensembl variation database tables.

Normally, the reference genome assembly used by Ensembl matches the one used in the current build of dbSNP. When this is the case, the variant mapping positions can be imported directly from dbSNP and are therefore in sync with the rest of the data in Ensembl. As the genome browser at UCSC also uses the dbSNP variant mappings, using the same assembly is good for consistency across the major genome browsers.

In some cases however, the current genome assembly supported by Ensembl is ahead of the one used in the most recent build of dbSNP. When this occurs, the vari- 
Table 1: Variation statistics for release 56, September 2009 http://sep2009.archive.ensembl.org/index.html.

\begin{tabular}{|c|c|c|c|}
\hline Name & Number of variants ** & Genome size* (Assembly name) & Data source of variants \\
\hline Homo sapiens & $17,999,182$ & $3,101,804,741$ (GRCh37) & dbSNP; Resequencing reads \\
\hline Pan troglodytes & $1,520,077$ & 3,350,417,645 (CHIMP2.1) & $\mathrm{dbSNP}$ \\
\hline Pongo pygmaeus abelii & $1,384,342$ & 3,446,771,396 (PPYG2) & Assembly Reads \\
\hline Mus musculus & $14,888,174$ & $2,716,965,481$ (NCBIM37) & dbSNP; Resequencing reads \\
\hline Rattus norvegicus & $2,854,253$ & 2,718,897,321 (RGSC3.4) & dbSNP; Resequencing reads \\
\hline Canis familiaris & $3,057,889$ & $2,531,673,953$ (BROADD2) & $\mathrm{dbSNP}$ \\
\hline Bos taurus & $2,057,872$ & 2,918,205,644 (Btau_4.0) & $\mathrm{dbSNP}$ \\
\hline Ornithorhynchus anatinus & $1,207,507$ & $2,073,148,626$ (OANA5) & Assembly reads \\
\hline Gallus gallus & $2,960,841$ & $1,100,480,441$ (WASHUC2) & dbSNP \\
\hline Danio rerio & 617,481 & $1,481,257,891(Z v 8)$ & $\mathrm{dbSNP}$ \\
\hline Tetraodon nigroviridis & 903,588 & $358,618,246$ (TETRAODON8) & Assembly reads \\
\hline Taeniopygia guttata & $4,745,545$ & $1,233,169,488$ (taeGut3.2.4) & Assembly reads \\
\hline
\end{tabular}

ants and their flanking sequences need to be remapped to the new assembly using a method in the core Ensembl API. For those variants that fail to map, new mappings are obtained using ssaha2, an improved version of SSAHA http://www.sanger.ac.uk/resources/software/ ssaha2/[24]. The flanking sequence is aligned with the parameters $\mathrm{kmer}=12$ seed $=4 \mathrm{cut}=1000$ depth $=5$ best $=$ 1. For species with shorter flanking sequences, such as the zebrafish, seed $=2$ is used.

The effect of this procedure is to ensure that dbSNP variation data in Ensembl is mapped to the most recent genome assembly supported by Ensembl, even if the assembly is not yet supported by dbSNP. As noted above, when the new dbSNP build is released, Ensembl is updated with the dbSNP defined variant positions. For a very small number of SNPs, this dbSNP update will result in changes to the SNP locations that had been defined by the Ensembl mappings on the new assembly. These changes are due to the method of incorporation of newly submitted data by reclustering of the variants as part of each dbSNP build.
Genotype data is imported from dbSNP and integrated with the polymorphism data described above. For example, in release 56 Ensembl has genotype data for 8335 individuals from a number of reference data sets including the HapMap [25], Perlegen [26] and the 1000 Genomes Project [2].

\section{Array Data: Illumina, Affymetrix}

Primary identifiers are assigned to variations. Usually these are from dbSNP (rs and ss identifiers). However, there may be other sources for variations. Names in these other datasets are only used as primary IDs if there is no matching dbSNP record. In the case of a dbSNP record, the IDs from other datasets are included as synonyms.

As of release 56 (September 2009), Ensembl imports variants positions from the following arrays: Affymetrix GeneChip Human Mapping 100 K Array Set, Affymetrix GeneChip Human Mapping 500 K Array Set, Affymetrix Genome-Wide Human SNP array 6.0, Illumina whole genome SNP genotyping chips designed for association studies (Human 660W-Quad, Human 1M-Duo V3) and for cytogenetic analysis (Cyto SNP-12 v1). 
Table 2: List of Ensembl tables generated and dbSNP tables used

\begin{tabular}{|c|c|}
\hline Ensembl tables generated & dbSNP tables used \\
\hline \multicolumn{2}{|l|}{ source } \\
\hline variation & SNP, SNPAncestralAllele \\
\hline \multirow[t]{2}{*}{ variation synonym* } & SubSNP, SNPSubSNPLink, ObsVariation \\
\hline & Batch, UniVariAllele \\
\hline population/sample/population structure/sample synonym & PopClassCode, PopClass, PopLine \\
\hline individual/sample/individual population/sample synonym & SubmittedIndividual, Individual Pedigreelndividual \\
\hline allele & Allele, AlleleFreqBySsPop, SubSNP \\
\hline flanking sequence & SubSNPSeq5, SubSNPSeq3, SNP \\
\hline individual genotype & Sublnd, ObsGenotype, Submittedlndividual \\
\hline population genotype & GtyFreqBySsPop, UniGty, Allele \\
\hline variation feature & SNPContigLoc, ContigInfo \\
\hline
\end{tabular}

\section{Legacy variation identifiers}

Previously, Ensembl provided the identification page numbers from The SNP Consortium [9] and HGVBase [27] as synonyms to the primary variation identifiers. These identification numbers were prefaced with codes TSC and SNP respectively. As neither of these databases is active the identification numbers have been removed from the current database but are still accessible via the Ensembl Archive websites http://www.ensembl.org/info/ website/archives/index.html and available by FTP ftp:// ftp.ebi.ac.uk/pub/software/ensembl/snp/.

\section{Phenotype data}

Ensembl currently imports phenotype data from two sources: The National Human Genome Research Institute's (NHGRI) Office of Population Genomics and from the European Genome-phenome Archive (EGA) database [28].

NHGRI has developed a curated database of published significant genomic regions identified from genome-wide association studies http://www.genome.gov/GWAstudies[29]. More regions are being added as additional GWAS studies are published. These data are updated for every release of Ensembl.

The EGA database at the European Bioinformatics Institute is designed to provide a permanent archive for all types of personally identifiable genetic data including genotypes, genome sequence, and associated phenotype data.

In Ensembl release 56 (September 2009), data from these two resources total 134 phenotypes from 1120 possible phenotype annotations associated with 142 different variants. There is a direct link from the web page to the original submitter's data entry under the "Source" column in order to acknowledge the contributor directly. In addition a link is provided to the publication record in PubMed.

\section{Data generation}

\section{Algorithm for Variant discovery from Sequencing reads}

Ensembl provides the location of specific variants in individuals, laboratory strains and breeds. These variants are calculated as described here using publicly available Sanger-style resequencing data such as from the Ensembl Trace Archive or from whole genome projects that sequence a single individual (with both haplotypes) or small number of individuals. By aligning the sequencing reads to the reference assemblies for the same species, Ensembl is able to identify any heterozygous sites in the sequenced individual by mismatches in the alignment [4]. These alignments are determined using the ssahaSNP pipeline http://www.sanger.ac.uk/resources/software/ ssahasnp/[24] and require both the sequence data and 
sequencing quality PHRED scores in order to ensure high quality. Using the neighbourhood quality score (NQS) method [30], SNPs were called from alignments only when the variant base in the sequencing read had PHRED quality value greater than or equal to 23 , the five bases on each side of the variant aligned exactly to the assembly with PHRED quality scores greater than 15 and when there was no more than one mismatch in 10 flanking base pairs.

Furthermore, potential variants are filtered and discarded if they have more than 30 mismatches from a single sequence read or are in a region with more than 100 aligned reads. (These values are reduced if the sequencing coverage is less than approximately $0.1 \times$ ). Read pair information is used to filter out wrongly mapped reads, and variants with more than two alleles for one strain/ individual are discarded. For individuals or strains with a read coverage of greater than 3, a SNP will be reported if at least two reads have the minor allele.

Ensembl also examines the resequencing reads that align to known SNP loci in order to verify the sequence of the resequenced individual at these locations. If there is sufficient evidence (defined with the same quality metrics as above) to determine that the given individual does not have an alternative allele at the tested location, this information is stored in the database as a "SARA" (Same As Reference Assembly) position, which can be thought of as a computational genotyping assay.

A representation of the resequencing coverage for several mouse and rat strains as well as the Watson and Venter genome sequences is stored in the variation database as a range of start and end coordinates with an indication of the level of read coverage.

The variation database generated by Ensembl's SNP calling pipeline is then merged with the variation database imported from dbSNP. Part of the merging procedure involves modifying all of the dbSNP imported variants to represent them on the positive strand. A variant by Ensembl from resequencing data that has the same locus as one already in dbSNP is assigned the rsID from dbSNP for that locus as the primary ID; those not yet in dbSNP can be identified by the Ensembl style identifiers and are submitted by Ensembl to dbSNP.

\section{Data quality checks}

Once the database has been populated with variation data, a series of post processing steps is performed to ensure data consistency and quality. Variants observed multiple times (e.g. in data imported from dbSNP and created by analysis of the Ensembl Trace Archive) are collapsed into a single record with supporting identifiers stored as synonyms.

Variants are considered unreliable and flagged as "failed" if they exhibit any of the following characteristics: variants which map more than three times; those which do not map to the genome; those with no observed allele matching the reference allele; those with more than three observed alleles. Failed variants remain in the database but have no associated mapping position. There is also a checklist to ensure those medically important or other known to be correct variants that exhibit one of the above characteristics are not moved inadvertently to the failed variation table. Approximately 689660 variants are classified as failed across all supported species in release 56 (September 2009) (see Table 3).

\section{Variation consequence annotation}

Once a list of reliable variants has been identified, they are integrated with the Ensembl gene annotations in order to estimate the consequence of each variant on all transcripts. A list of possible consequences assigned in shown in Table 4. This section of the pipeline is recalculated whenever the gene sets for a species is updated.

Variants are associated with transcripts if they are located within transcript or intron sequences, within 5 $\mathrm{KB}$ of a transcript start or end, or if they are located within a regulatory region associated with a gene or transcript. Ensembl ranks these "consequence types" in estimated order of importance, including any effect of the variant on the sequence of the final protein product. For example ESSENTIAL SPLICE SITE is considered one of the most important consequence types as it would have great affect on the protein product.

\section{Calculation of Linkage Disequilibrium (LD)}

The method used to calculate $\mathrm{LD}\left(\mathrm{r}^{2}\right.$ and $\left.\mathrm{D}^{\prime}\right)$ is described below. For each population with a sample size of at least 40 , variants are ordered by their positions and pairwise $\mathrm{LD}$ ( $\mathrm{r}^{2}$ values) are calculated within a $100 \mathrm{~kb}$ window size. If $r^{2}$ values are less than 0.05 they are discarded and the rest are stored in a table. This table is only used for the calculation of tagged SNPs and is not present in the final database. The $\mathrm{r}^{2}$ and $\mathrm{D}^{\prime}$ values used in Ensembl web interface are calculated separately on demand [23].

\section{Calculation of tagged SNPs}

A list of tagged variants for haplotype analysis is produced for each of the HapMap and Perlegen populations and stored in the database. This is designed to choose common variants in each region of the genome (i.e. tag SNPs) from which the genotypes of surrounding SNPs in high LD can be derived. In order to store a minimal list, variants are selected per population and any other variants in high LD with this one are filtered out. To do this, variants that have genotypes are sorted by start position. For each variant, the MAF is calculated by population and then these are ordered by frequency with the highest MAF first. For each ordered variant, the pairwise $r^{2}$ value 
Table 3: Breakdown of failed variants by type for each species

\begin{tabular}{|c|c|c|c|c|c|c|}
\hline Name & Type 1 & Type 2 & Type 3 & Type 4 & Type 5 & Total number \\
\hline Homo sapiens & 132,037 & 494,262 & 37,456 & 3,359 & 13,768 & 680,882 \\
\hline Pan troglodytes & 0 & 0 & 7 & 0 & 2,885 & 2,892 \\
\hline Pongo pygmaeus abelii & 0 & 0 & 0 & 0 & 0 & 0 \\
\hline Mus musculus & 155,456 & 299,923 & 0 & 0 & 25,691 & 481,070 \\
\hline Rattus norvegicus & 1,475 & 482 & 1 & 0 & 216 & 2174 \\
\hline Canis familiaris & 27,518 & 15,660 & 55 & 0 & 11,986 & 55,219 \\
\hline Bos taurus & 9,679 & 103,072 & 0 & 0 & 490 & 113,241 \\
\hline Ornithorhynchus anatinus & 0 & 4849 & 0 & 0 & 0 & 4,849 \\
\hline Gallus gallus & 11,070 & 88,558 & 0 & 0 & 229,878 & 329,506 \\
\hline Danio rerio & 0 & 0 & 0 & 0 & 44,841 & 44,841 \\
\hline Tetraodon nigroviridis & 0 & 0 & 0 & 0 & 0 & 0 \\
\hline Taeniopygia guttata & 0 & 0 & 0 & 0 & 0 & 0 \\
\hline
\end{tabular}

Type 1: Variant maps to more than 3 different locations

Type 2: None of the variant alleles match the reference allele

Type 3: Variant has more than 3 different alleles

Type 4: Loci with no observed variant alleles in dbSNP

Type 5: Variant does not map to the genome

for all variants within a $100 \mathrm{~KB}$ is extracted from the $\mathrm{LD}$ table described above. If the $\mathrm{r}^{2}$ value between the variations is greater than 0.99 (i.e. the two variants are in high LD), the associated variant with the lower MAF is removed from the list. This process removes variation data in high LD with other variants that have lower MAF. The remaining variations are called tagged SNPs and are stored in the database.

\section{Utility and access of variation data}

As with all Ensembl databases, the data is accessible in multiple ways: either programmatically via the Ensemblstyle Application Program Interface (API) [23], or online using the Ensembl genome browser visualisation tools and the Ensembl BioMart tool. Ensembl's variation specific web displays, along with a variation focused BioMart query, are described in detail below. To facilitate bioinformatics analysis, the Ensembl databases are publicly available at the MySQL database server on ensembldb. ensembl.org and the BioMart databases at martdb.ensembl.org.

\section{Data Visualisation}

Ensembl provides a number of specialised and highly interactive web displays focusing on four levels: a genomic location, a gene, a transcript and a variation. These four types of view support distinct pathways into the data (Table 5), and are reflected by the four main tabs in the Ensembl interface. This allows researchers to explore complementary information from various perspectives. It is possible to customise most views in Ensembl using the "configure this page" link at the left of the web pages. The first tab considered, the variation tab, is available for all species with variation data within Ensembl (see the first column of Table 1).

The variation tab

Consider the variation rs2476601, which has been wellstudied (see for example http://www.snpedia.com/index. 
Table 4: List of consequence types in the transcript variation table

\begin{tabular}{|c|c|c|}
\hline Consequence type & Effect & Sequence location \\
\hline Stop gained & causes a gain of a stop codon & coding sequence of the peptide \\
\hline Stop lost & causes a loss of a stop codon & coding sequence of the peptide \\
\hline complex InDel & change in nucleic acid & Indel spanning exon/intron or CDS/UTR border \\
\hline Frameshift coding & causes a frameshift of the reading frame & affects the coding sequence of the peptide \\
\hline Stop gained, frameshift coding & $\begin{array}{l}\text { multi-allelic variant that introduces a stop } \\
\text { codon or causes a frameshift }\end{array}$ & affects the coding sequence \\
\hline Non-synonymous coding & causes an amino acid change & coding sequence of the peptide \\
\hline Stop gained, splice site & causes a gain of a stop codon & 1-3 bps into an exon \\
\hline Stop lost, splice site & causes a loss of a stop codon & 1-3 bps into an exon \\
\hline Frameshift coding, splice site & causes a frameshift & 1-3 bps into an exon \\
\hline stop gained, Frameshift coding, splice site & $\begin{array}{l}\text { Multi-allelic variant that introduces a stop } \\
\text { codon or causes a frameshift }\end{array}$ & $1-3$ bps into an exon \\
\hline Non-Synonymous coding, splice site & causes an amino acid change & $1-3$ bps into an exon \\
\hline Synonymous coding & $\begin{array}{l}\text { change in nucleic acid but no change in } \\
\text { amino acid }\end{array}$ & coding sequence of the peptide \\
\hline Splice site, synonymous coding & $\begin{array}{l}\text { change in nucleic acid but no change in } \\
\text { amino acid }\end{array}$ & $1-3$ bps into an exon \\
\hline Regulatory region & change in nucleic acid & regulatory region annotated by Ensembl \\
\hline Within mature miRNA & change in nucleic acid & within mature miRNA \\
\hline 5' UTR & change in nucleic acid & In 5' UTR \\
\hline Splice site, 5' UTR & change in nucleic acid & 1-3 bps into a 5' UTR exon \\
\hline 3' UTR & change in nucleic acid & In 3' UTR \\
\hline Splice site, 3' UTR & change in nucleic acid & 1-3 bps into a 3' UTR exon \\
\hline Intronic & change in nucleic acid & In intron \\
\hline Essential splice site, intronic & change in nucleic acid & in the first 2 or the last 2 base pairs of an intron \\
\hline Splice site, intronic & change in nucleic acid & 3-8 bps into an intron \\
\hline
\end{tabular}


Table 4: List of consequence types in the transcript variation table (Continued)

\begin{tabular}{lcc}
\hline Upstream & change in nucleic acid & Within $5 \mathrm{~kb}$ upstream of the 5'-end of a transcript \\
\hline Downstream & change in nucleic acid & Within $5 \mathrm{~kb}$ downstream of the 3'-end of a transcript \\
\hline Within non-coding gene & change in nucleic acid & Within non-coding gene \\
\hline Intergenic & change in nucleic acid & More than $5 \mathrm{~kb}$ away from a transcript \\
\hline
\end{tabular}

php?title=Rs2476601) and has been implicated in rheumatoid arthritis [31], among other diseases. Entering rs2476601 in the search box at http://www.ensembl.org returns a link to the variation tab, described below. A search for a disease or phenotype will also link to the variation views.

The variation tab contains data reports for one specific variation. A menu of links to these reports is available at the left hand side of the variation tab Figure 1, label 1. The variation identifier at the top of the variation summary is the dbSNP rs identifier, if one exists, otherwise the ss identifier or local identifier is chosen. Where appropriate, there is a link to the corresponding variation page in the dbSNP browser. The synonyms field (Figure 1, label 2) shows additional names for the variant, for example dbSNP ss IDs and IDs from other sources including Affymetrix SNP arrays and Illumina platforms, as described above. Flanking sequence, as reported by the dbSNP database, is shown on the page as are links to LD (linkage disequilibrium) plots, if available.

Table 5: Variation Displays in the Ensembl website

\begin{tabular}{ll}
\hline Browser Object & Sub Panel \\
\hline Location & $\begin{array}{l}\text { resequencing data } \\
\text { linkage data }\end{array}$ \\
\hline Gene & variation table \\
& variation image \\
\hline Transcript & population comparison \\
& comparison image \\
\hline Variation & summary \\
& gene/transcript \\
& population genetics \\
& individual genotypes \\
& context \\
& phenotype data \\
& phylogenetic context \\
\hline
\end{tabular}

LD plots Following the link to an LD plot displays the LD data calculated within a region (Figure 2). The variation sources represented by the LD plot are customisable. Below the transcript diagrams there is a track showing all variations (Figure 2, label 1), a track showing only genotyped variations (label 2) and a track for tagged variants (label 4). Using the conventions described above and listed in Table 4, these tracks are colour-coded according to their location/effect on the transcript (label 3). Below this are LD $r^{2}$ and LD $D^{\prime}$ plots. The data for these plots, as described above, is calculated on-the-fly using a standard EM algorithm for calculating LD. The export data link at the left of the page will generated downloadable files of pairwise $r^{2}$ and $D^{\prime}$ values along with rs IDs, in HTML, text, or Microsoft Excel format. The data can also be exported in a format for uploading into Haploview software [32].

Variation links Links at the left of the page (Figure 1, label 1) are to views that provide information about the variation summary, the genes or transcripts in Ensembl associated with this variation, population allele and genotype frequencies imported from dbSNP, individual genotypes, a graphical view of the variation and neighbouring variations (the context link), phenotype data from the manually curated NHGRI GWAS catalogue and European Genome- phenome Archive http://www.ebi.ac.uk/ ega/, and the phylogenetic context of the variant showing the allele at this position across species (including calculated Ensembl ancestral alleles) (Figure 3).

Gene/Transcript link A table displays any transcript in Ensembl associated with the variant. The predicted effect of the variant is listed (e.g. intronic, synonymous coding, etc.) along with the position of the allele in the spliced transcript and protein. These values can be exported using BioMart.

Population genetics Data from projects such as The HapMap Project or Perlegen are included in this view. Allele frequencies are displayed for specific populations, along with a summary of genotype information.

Individual genotypes This next view shows a breakdown of genotypes for each individual stored in the database. 


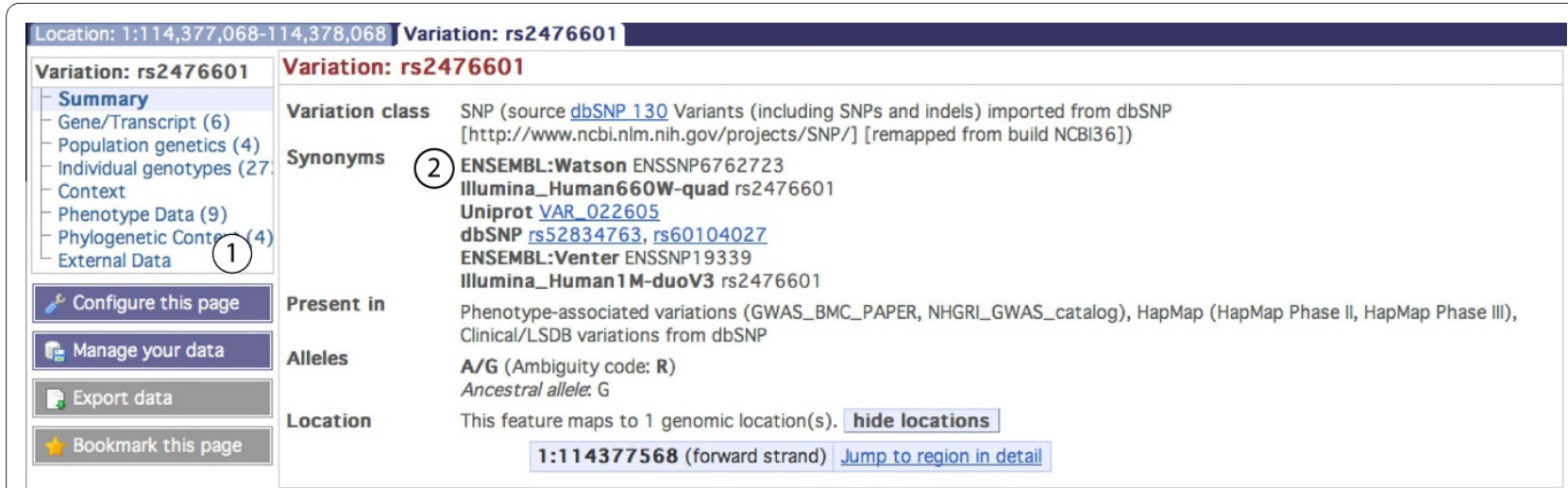

Figure 1 Variation summary for rs2476601. Label 1 indicates the links to information for this specific variant. Label 2 indicates the summary, which includes the source (dbSNP), synonyms or other IDs for this variant in other databases or array platforms, alleles found and genomic location. Flanking sequence is also found in the summary information but not shown in the figure. http://Mar2010.archive.ensembl.org/Homo sapiens/Nariation/Summary? source $=\mathrm{dbSNP} ; \mathrm{v}=\mathrm{rs} 2476601$.

Context The variant of interest is shown by default in a $30 \mathrm{~Kb}$ region with neighbouring SNPs as boxes and indels as triangles. Variation colour-coding is consistent throughout the Ensembl website and depend on the variant's localisation within a transcript (table 3).

Phenotype data Listed in tabular format are any associated diseases, appropriate study and PubMed references, associated genes, the highest-risk allele and associated variant.

Phylogenetic context This view displays a section from a whole-genome, multi-species alignment in this region. These alignments, including the calculated ancestral sequences are produced by Ensembl's three step EnredoPecan-Ortheus (EPO) pipeline [33,34]. Briefly, the pro-

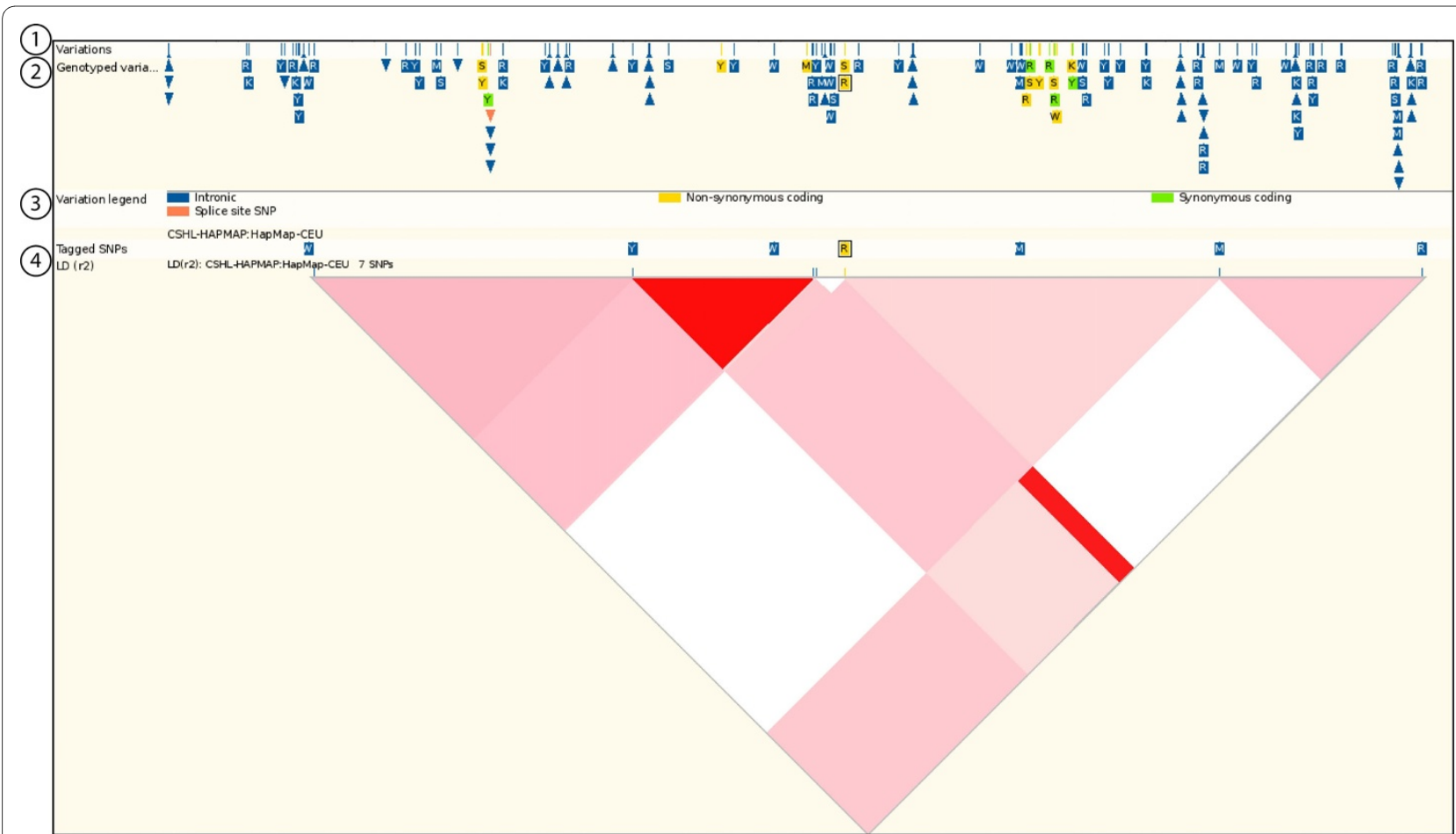

Figure 2 LD (linkage disequilibrium) plot for the region around rs2476601. LD values in this figure were calculated based on allele frequencies in the CEPH human population. The LD data between variants is represented using a triangular grid shaded on a gradient from white to red depending on the strength of the LD (where red is high LD, white is low). Hovering the mouse cursor over one of the coloured regions in the plot reveals a popup box displaying the two variation IDs for that coloured region, and the LD value between them. http://Mar2010.archive.ensembl.org/ Homo sapiens/Location/LD?focus=variation;pop1=CSHL-HAPMAP:HapMap-CEU;r=1:114367568-114387567;v=rs2476601;vf=1916990. 


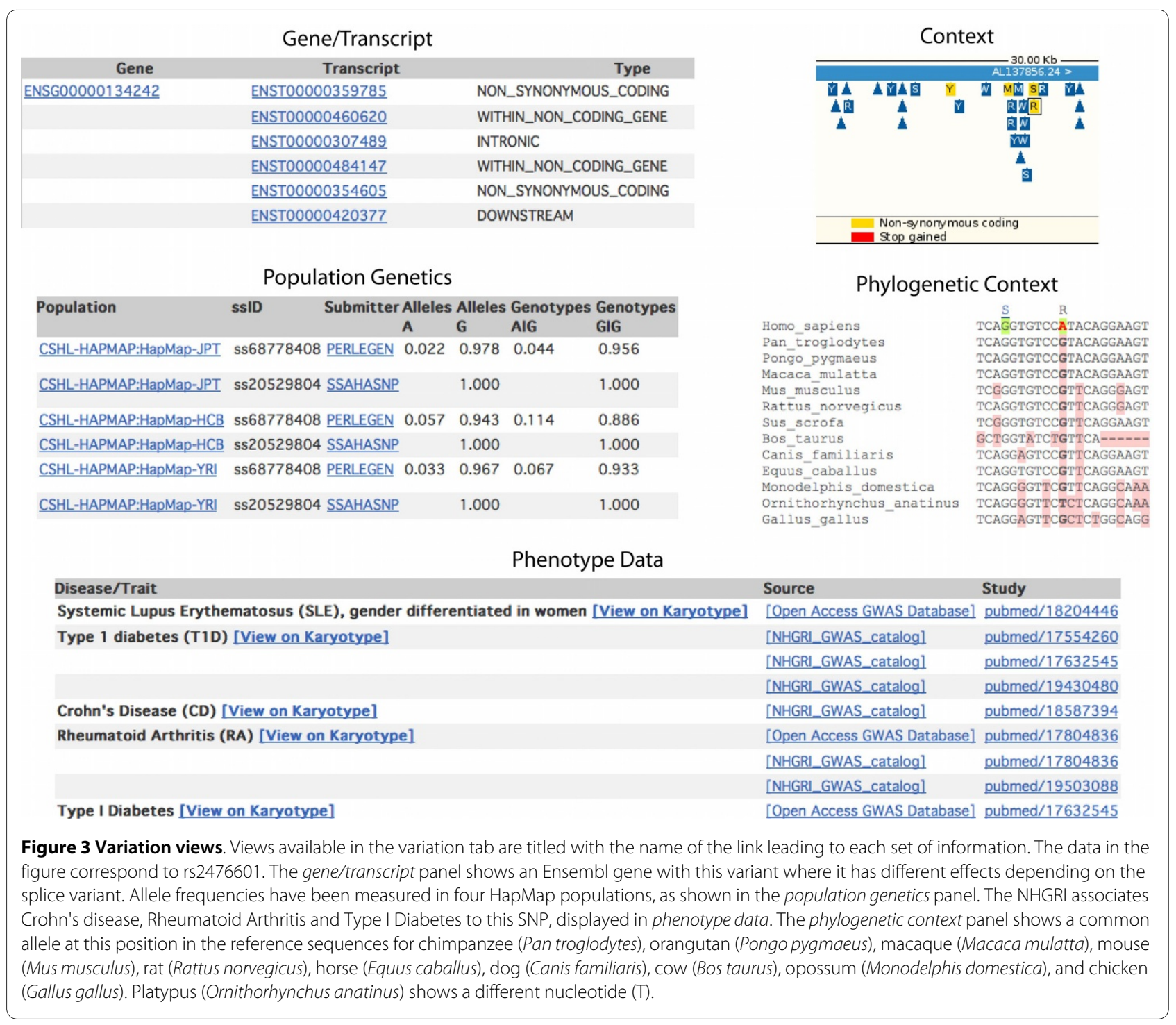

cess consists first of Enredo, which produces the initial collinear segments that appropriately take into consideration rearrangements, deletions and duplications from the genomes to be aligned. In the second step, the consistency-based method Pecan aligns the sets of sequences identified by Enredo taking into account the phylogenetic tree of species to be aligned. Finally, Ortheus uses a probabilistic transducer model to create genome-wide ancestral sequence reconstructions.

\section{The gene tab}

Genetic variation: table and image Clicking on an Ensembl gene identifier or searching for a gene in the Ensembl search box (e.g. ENSG00000134242) moves the display to the gene tab. The gene tab provides links to the genetic variation table and the genetic variation image, which display the collection of known variation for a gene in a given species (Figure 4A, label 1).

In the variation table, each transcript (i.e. splice isoform) for the specific gene is shown, along with any asso- ciated variation. Effect on the transcript (if any), position in genomic coordinates, alleles, amino acids encoded and amino acid coordinates (if any) are listed. The source (or sources) of the variation and validation status are also shown.

The variation image (Figure 4) provides a graphical representation of this information. The addition of protein domains mapped to the amino acid sequences makes it possible to estimate any effect of a variation on protein structure and/or function.

Gene sequence The genomic sequence can be configured to highlight variant positions. Exons are highlighted in this view, allowing immediate visualisation of where a variation falls, in the context of a gene.

\section{The transcript tab}

Transcript variation: table and image The gene-based variation pages described in the section above compare and collate information across alternative transcripts for the reference sequence assembly. The transcript views 
provide an in depth focus on one transcript, or splice isoform, across individuals, breed or strains. A list of these views and links are shown at the left of figure 5 .

The transcript tab may be reached by clicking on any Ensembl transcript identifier link within the browser. All transcript identifiers (such as ENST00000359785) have the letter $\mathrm{T}$ immediately before the series of numbers. In the genetic variation section in the left hand menu of the transcript tab, the population comparison table and image can be found. The table lists all the variation for the transcript including details of genomic location, allele, variation source and validation status. The difference between this table and the one found in the gene tab is the ability to list variations across the genome sequences of individual humans, laboratory strains of rats and mice and breeds of dogs, chicken and other species.

The comparison image depicts information in the table, graphically (Figure 5). A track representing resequencing information is drawn below each transcript (Figure 5, label 1). A direct comparison of alleles across individuals, breeds or strains is shown (Figure 5, label 4).

cDNA sequence Variation data may be displayed on the spliced transcript sequence as in Figure 6. Select the cDNA link in the sequence section of the left hand menu in the transcript tab. Three sequence displays can be compared (cDNA, coding sequence, and protein) (Figure $6 \mathrm{~A})$.

In figure $6 \mathrm{~B}$, the red amino acid $\mathrm{R}$ at position 183 in the protein sequence (547 in the coding sequence, and posi-
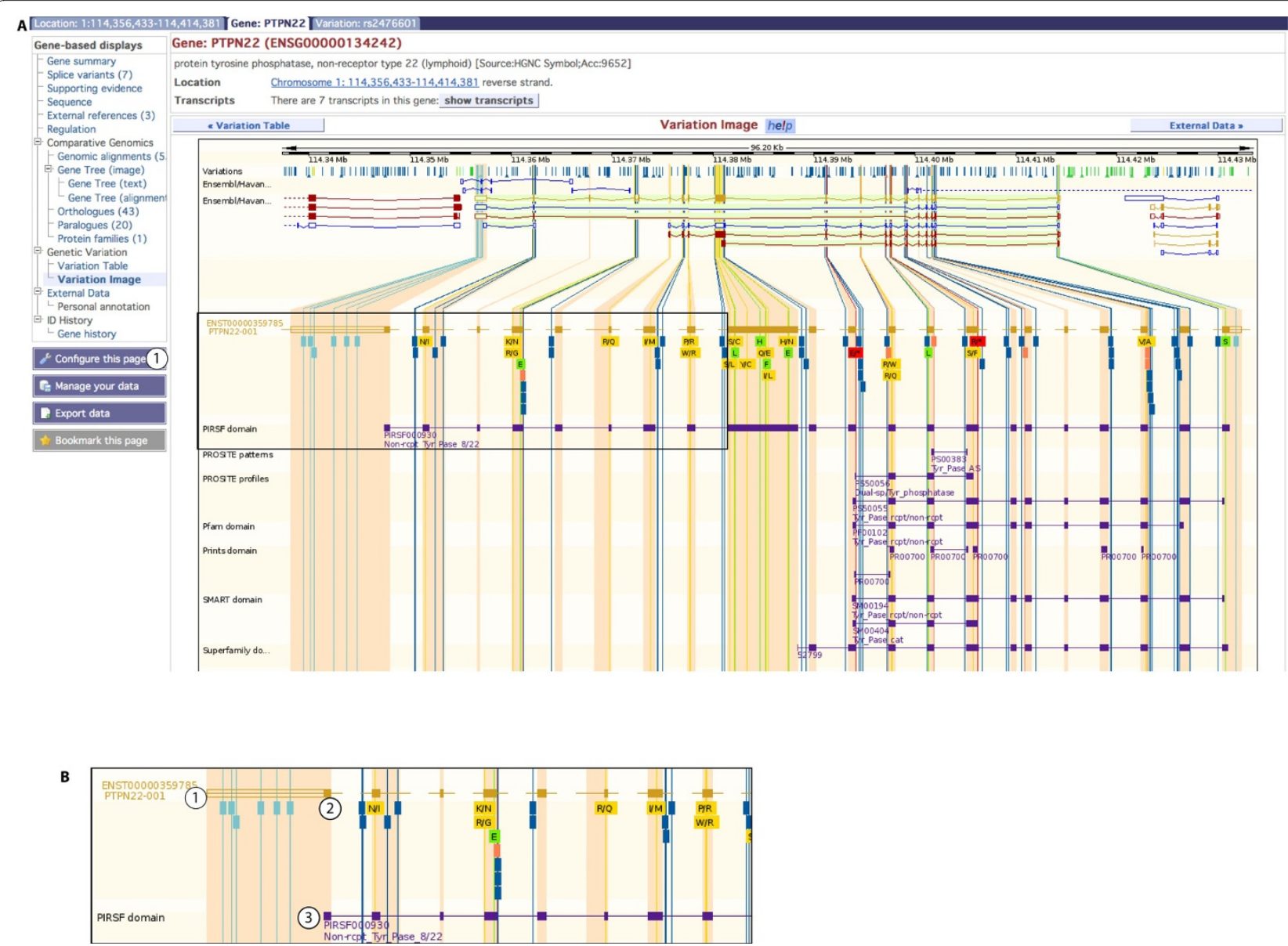

Figure 4 Variation image. A. The variation image in the gene tab shows all transcripts for an Ensembl gene in red, and variations mapping to each transcript as coloured boxes. Intronic variants are, by default, only drawn if within $100 \mathrm{bp}$ of an exon. Change this by clicking on configure this page and selecting full introns. Protein domains and motifs encoded by the transcript sequence from databases such as PIR-Superfamily, PROSITE and Pfam are drawn in purple along each transcript. B. An expanded view of the box drawn in $\mathbf{A}$ is shown. Label 1 indicates the exon structure of Ensembl transcript ENST00000359785. Filled boxes are coding sequence within the exons, and unfilled boxes indicate untranslated regions (UTRs). Variations are indicated by label 2, and are colour-coded as to their effect on the transcript (see legend on the page). For this transcript, many intronic (dark blue) variations are shown, along with four non-synonymous (yellow) SNPs that display the potential amino acids at each position. Label 3 indicates a PIRSuperfamily domain (purple) that maps to the protein sequence. http://Mar2010.archive.ensembl.org/Homo sapiens/Gene/ Variation Gene? $\mathrm{db}=\mathrm{core} ; \mathrm{g}=$ ENSG00000134242; $\mathrm{r}=1: 114356437-114414375 ; \mathrm{t}=$ ENST00000359785. 


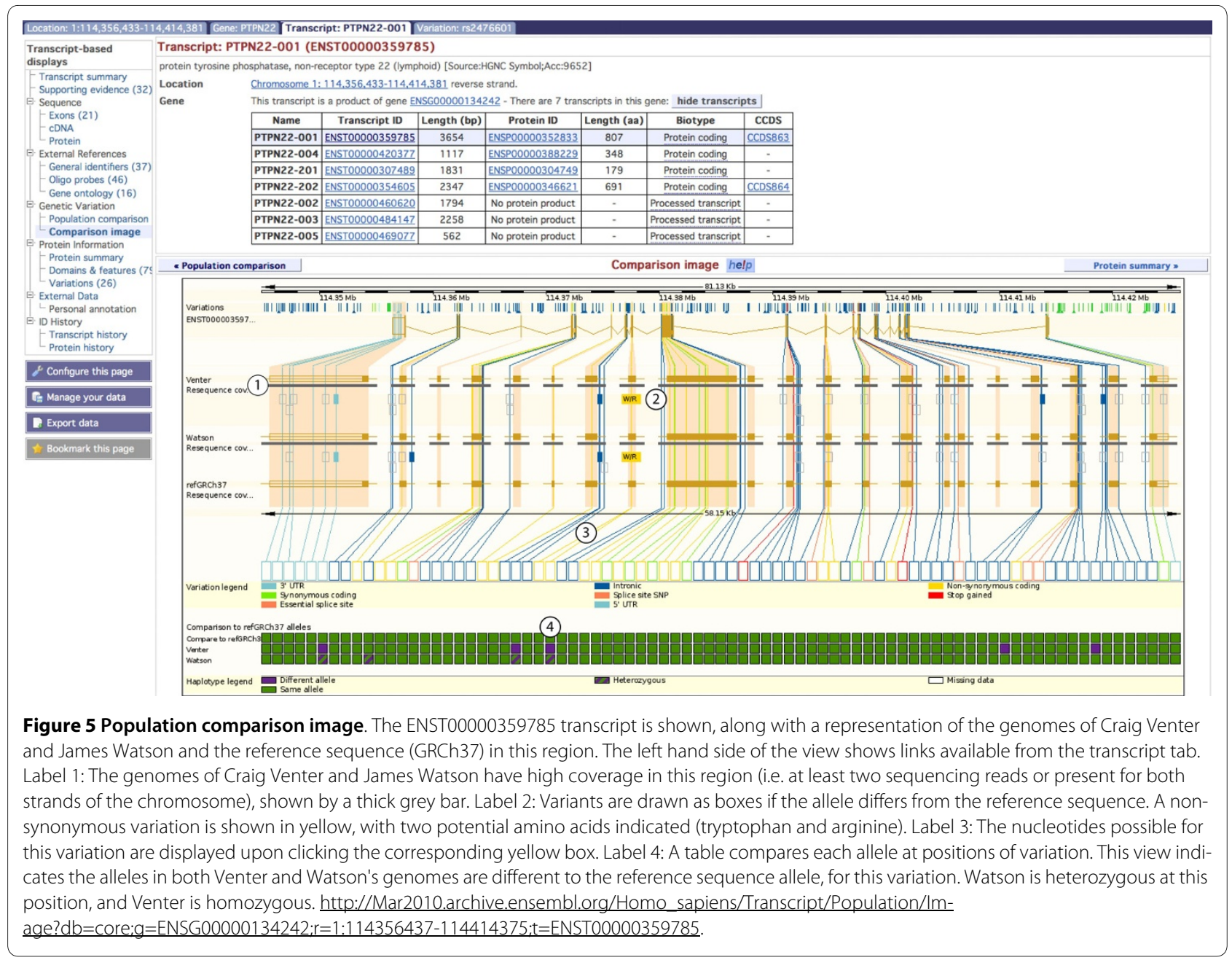

tion 677 in the transcript sequence) indicates a non-synonymous variation.

\section{The location tab}

The fourth and final tab described in this section contains location-based views, showing a region of the genome. View this tab by selecting it, or by clicking on any genomic coordinates-range presented in the browser. This tab was already visited in the data visualisation section of this paper as it houses the LD plots.

Variation data may be displayed in the genomic alignments view, highlighted where present in the sequence of the multiple species alignments. Variants can also be drawn in the region overview and region in detail views. Here, variations are displayed as vertical lines along the genome, colour-coded by the effect on the transcript. Turn variations on and off in these displays by clicking on configure this page and selecting the appropriate options. Resequencing The genetic variation section of the location tab shows a link to the resequencing alignments. These are sequence alignments across individuals, strains (for mouse, rat) or breeds (for dogs). In the example shown in figure 7, Venter and Watson's diploid genomes are compared with the reference sequence, GRCh37.

\section{Data export with BioMart}

The BioMart tool utilises denormalised Ensembl databases and can be used to query the Ensembl core or variation databases [17]. As no programming is required, the tool may be especially useful for scientists with little computer experience. The BioMart tool is accessible from the top right of all Ensembl pages as well as from the BioMart portal at http://www.biomart.org.

Starting a BioMart query and choosing the Ensembl database (for release 56, this is listed as "Ensembl 56" from the dropdown menu, where 56 refers to the September 2009 version of Ensembl) allows gene-specific information to be exported. For example all variation for a gene can be exported in tabular format. In addition, a user may input a list of gene IDs, a region, or even an entire chromosome to mine genes and associated variations.

The Ensembl variation database may also be selected as the starting point for a BioMart query. This allows input 


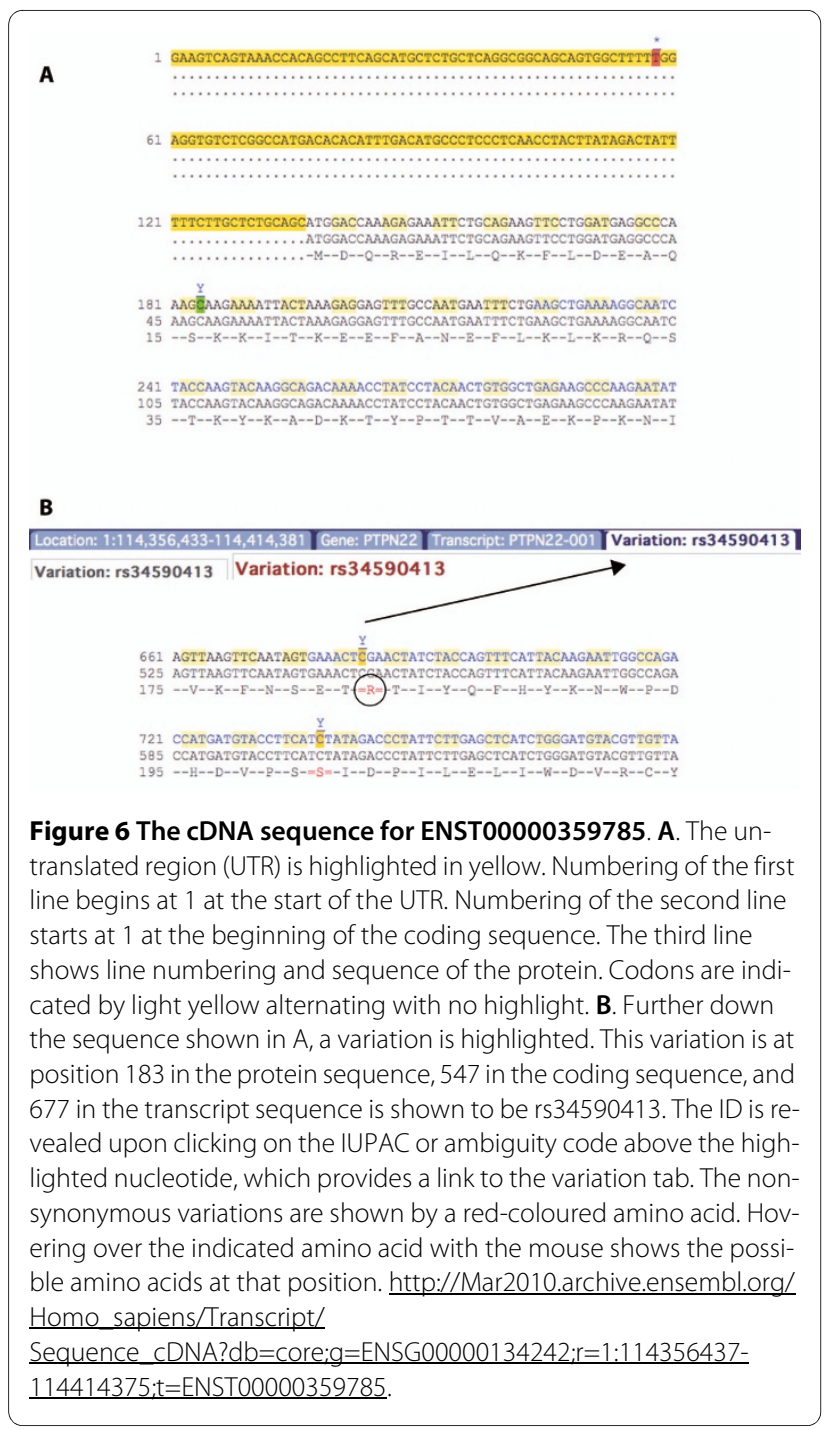

of variation IDs, and is not contingent upon a gene annotation (i.e. intergenic regions are allowed). Furthermore, variations can be compared across populations, strains or breeds, starting with the variation database and using the "strain polymorphisms" attributes page. Export includes tabular formats such as csv, tsv, and Microsoft Excel. Alternatively, FASTA sequences can be exported.

These BioMart queries can also be run programatically using a Perl API or through Web Services. Although the programmatic scripts can be written from scratch, the simplest way to access these interfaces is to build the variation query using the BioMart website and then use the "Perl" or "XML" buttons in the toolbar to produce the appropriate API or Web Services queries.

Additional information about BioMart queries is available from the BioMart help pages at http://www.biomart. org/biomart/mview/help.html and FAQ at http://www. biomart.org/faqs.html. Video BioMart tutorials are also

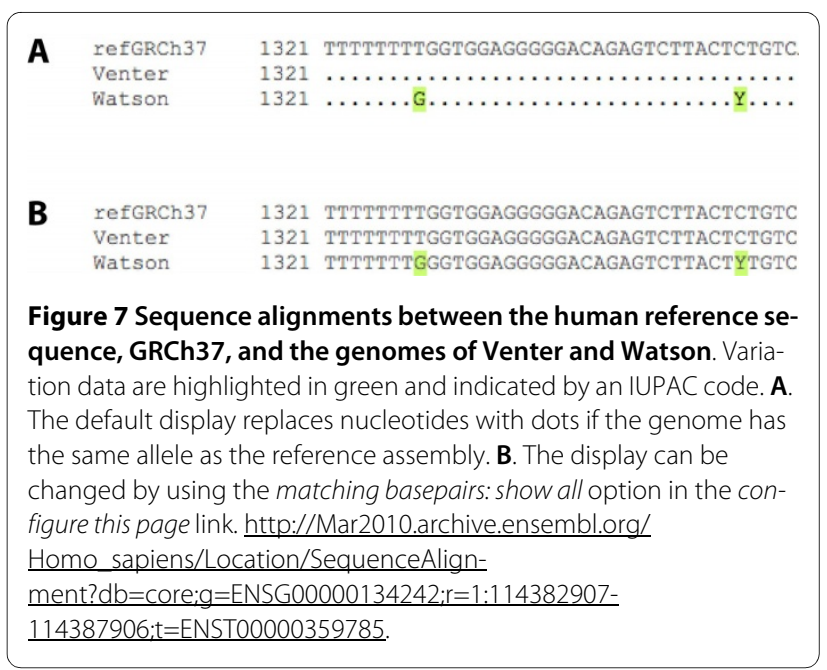

provided at http://www.youtube.com/watch?v=DXPaBd PM2vs\&feature=channel page.

\section{Data access using the API}

Advanced data mining is possible through direct MySQL queries of the Ensembl public database server at ensembldb.ensembl.org or by using the Ensembl variation API [23].

\section{Data downloads}

For convenience, Ensembl data is also available in species-specific files on the FTP site http://www.ensembl. org/info/data/ftp/index.html. This includes sequence data in FASTA format, annotation in EMBL, GENBANK and GTF format and SQL files for the databases. Resequencing data is provided for supported species in a flat file format termed EMF (Ensembl Multi Format) which is a compact, genome wide representation of the data shown in the resequencing display on the website, as described above.

\section{Future developments}

New data is expected to greatly increase the already vast variation information in Ensembl databases. The 1000 Genomes Project is generating a large number of individual reads and variation data that will be integrated into Ensembl. There is also additional reference copy number and structural variation $(\mathrm{CNV} / \mathrm{SV})$ data planned to be incorporated from the Database of Genomic Variants [35] and other public archives that store CNV/SV data. This will also certainly result in new or enhanced web displays for these data.

The publication of many new genome wide association studies are expanding the list of alleles that can be reliably linked to disease phenotypes and both associated and causative variants will be incorporated into Ensembl as they are identified. Additionally, as part of the LRG proj- 
ect [36] (http://www.lrg-sequence.org/) and in collaboration with the NCBI, Ensembl is working to establish locus-specific reference sequences. These LRG (Locus Reference Genomic) sequences can be used as a framework for data exchange of annotated disease variants currently stored in diagnostic laboratories and LSDBs (Locus-Specific Databases). Both of these developments will greatly enhance the existing phenotype annotation in the Ensembl variation databases.

Other future developments include more interactive analysis of user's variation data through the Ensembl web site including an online-based upload tool for which will enable users to upload their own set of variant positions and for these to be viewable on the genome browser and for Ensembl to estimate their effects based on their relative positions to the Ensembl gene sets.

\section{Conclusions}

Ensembl's variation resources provide a comprehensive and integrated resource for biologists and bioinformaticians to support a wide variety of research applications.

Continuously increasing biological information sources require effective and integrated bioinformatics tools and visualisation that relatively few sources are able to provide.

Ensembl's variation resources provide several advantages for users. The resources are fully integrated within to the Ensembl genome browser and with the high-quality Ensembl gene sets in order to estimate the consequences of each variant. The data is updated with each Ensembl release including automatic mapping when new genome assemblies are released, such that Ensembl's variation data may be provided in advance of a new dbSNP build. Given the breadth of species available within Ensembl, it is also easy to compare the information across many vertebrate and model organism species. Another strength of Ensembl is the availability of all its resources for free and in a variety of ways to suit a range of users as described in the availability section below. In particular, the variation API is unique among other large-scale integrative bioinformatics projects.

Finally, Ensembl is a service-focused resource. Comprehensive instructions and additional details about the project can be found at http://www.ensembl.org/info/ website/help/index.html. There are video tutorials and PDFs to provide a walk-through of variation displays on the website:

http://www.ensembl.org/info/website/tutorials/index. $\mathrm{html}$. Requests for assistance with any specific example or display can be addressed to

helpdesk@ensembl.org

\section{Availability}

All Ensembl data and source code are freely available for any purpose and may be downloaded in their entirety from http://www.ensembl.org. Each Ensembl release is maintained as an archive web site for at least two years after the date of initial release (see http://www.ensembl. org/info/website/archives/index.html). Ensembl is updated approximately every two months with new data, genome assemblies, and sequenced genomes. Not every species has sufficient new data to warrant an update for each release. The current release number and month of release are shown at the bottom of every Ensembl web page.

\section{Authors' contributions}

The database resources were created by YC, WM, DR, and FC. The variationspecific web displays were created by FC, EK, JS, BP and SB with input from all of the other authors. PMG and DS developed specific software for Ensembl variation. GS created the tutorials. FC, PF and EB defined requirements and PF provided overall project supervision. The paper was written by FC, PF, YC, GS and DS with input from all of the other authors. All authors read and approved the final manuscript.

\section{Acknowledgements}

We thank all of the Ensembl users, especially those who have taken the time to contact us with suggestions and other helpful comments.

The Ensembl project is funded primarily by the Wellcome Trust. Additional funding for Ensembl's variation resources comes from EMBL, the European Union Framework 6 STAR project, European Union Framework 7 Programme GEN2PHEN project and the UK Medical Research Council. We thank the other members of the greater Ensembl group at the EBI and the WTSI and Guy Coates, Pete Clapham and Tim Cutts for maintaining the Ensembl computer systems.

\section{Author Details}

'European Bioinformatics Institute, Wellcome Trust Genome Campus, Hinxton, Cambridge, CB10 1SD, UK and 2Wellcome Trust Sanger Institute, Wellcome Trust Genome Campus, Hinxton, Cambridge, CB10 1SA, UK

Received: 10 September 2009 Accepted: 11 May 2010 Published: 11 May 2010

\section{References}

1. International HapMap Consortium, Frazer KA, Ballinger DG, Cox DR, Hinds DA, Stuve LL, Gibbs RA, Belmont JW, Boudreau A, Hardenbol P, Leal SM, Pasternak S, Wheeler DA, Willis TD, Yu F, Yang H, Zeng C, Gao Y, Hu H, Hu W, Li C, Lin W, Liu S, Pan H, Tang X, Wang J, Wang W, Yu J, Zhang B, Zhang Q, Zhao H, Zhao H, Zhou J, Gabriel SB, Barry R, Blumenstiel B, Camargo A, Defelice M, Faggart M, Goyette M, Gupta S, Moore J, Nguyen H, Onofrio RC, Parkin M, Roy J, Stahl E, Winchester E, Ziaugra L, Altshuler D, Shen Y, Yao Z, Huang W, Chu X, He Y, Jin L, Liu Y, Shen Y, Sun W, Wang H, Wang Y, Wang Y, Xiong X, Xu L, Waye MM, Tsui SK, Xue H, Wong JT, Galver LM, Fan JB, Gunderson K, Murray SS, Oliphant AR, Chee MS, Montpetit A, Chagnon F, Ferretti V, Leboeuf M, Olivier JF, Phillips MS, Roumy S, Sallée C, Verner A, Hudson TJ, Kwok PY, Cai D, Koboldt DC, Miller RD, Pawlikowska L, TaillonMiller P, Xiao M, Tsui LC, Mak W, Song YQ, Tam PK, Nakamura Y, Kawaguchi T, Kitamoto T, Morizono T, Nagashima A, Ohnishi Y, Sekine A, Tanaka T, Tsunoda T, Deloukas P, Bird CP, Delgado M, Dermitzakis ET, Gwilliam R, Hunt S, Morrison J, Powell D, Stranger BE, Whittaker P, Bentley DR, Daly MJ, de Bakker Pl, Barrett J, Chretien YR, Maller J, McCarroll S, Patterson N, Pe'er I, Price A, Purcell S, Richter DJ, Sabeti P, Saxena R, Schaffner SF, Sham PC, Varilly P, Stein LD, Krishnan L, Smith AV, Tello-Ruiz MK, Thorisson GA, Chakravarti A, Chen PE, Cutler DJ, Kashuk CS, Lin S, Abecasis GR, Guan W, Li Y, Munro HM, Qin ZS, Thomas DJ, McVean G, Auton A, Bottolo L, Cardin 
N, Eyheramendy S, Freeman C, Marchini J, Myers S, Spencer C, Stephens M, Donnelly P, Cardon LR, Clarke G, Evans DM, Morris AP, Weir BS, Mullikin JC, Sherry ST, Feolo M, Skol A, Zhang H, Matsuda I, Fukushima Y, Macer DR, Suda E, Rotimi CN, Adebamowo CA, Ajayi I, Aniagwu T, Marshall PA, Nkwodimmah C, Royal CD, Leppert MF, Dixon M, Peiffer A, Qiu R, Kent A, Kato K, Niikawa N, Adewole IF, Knoppers BM, Foster MW, Clayton EW, Watkin J, Muzny D, Nazareth L, Sodergren E, Weinstock GM, Yakub I, Birren BW, Wilson RK, Fulton LL, Rogers J, Burton J, Carter NP, Clee CM, Griffiths M, Jones MC, McLay K, Plumb RW, Ross MT, Sims SK, Willey DL, Chen Z, Han H, Kang L, Godbout M, Wallenburg JC, L'Archevêque P, Bellemare G, Saeki K, Wang H, An D, Fu H, Li Q, Wang Z, Wang R, Holden AL, Brooks LD, McEwen JE, Guyer MS, Wang VO, Peterson JL, Shi M, Spiegel J, Sung LM, Zacharia LF, Collins FS, Kennedy K, Jamieson R, Stewart J: A second generation human haplotype map of over 3.1 million SNPs. Nature 2007, 449:851-861.

2. The 1000 Genomes Project [http://www.1000genomes.org]

3. Mural RJ, Adams MD, Myers EW, Smith HO, Miklos GL, Wides R, Halpern A, Li PW, Sutton GG, Nadeau J, Salzberg SL, Holt RA, Kodira CD, Lu F, Chen L, Deng Z, Evangelista CC, Gan W, Heiman TJ, Li J, Li Z, Merkulov GV, Milshina NV, Naik AK, Qi R, Shue BC, Wang A, Wang J, Wang X, Yan X, Ye J, Yooseph S, Zhao Q, Zheng L, Zhu SC, Biddick K, Bolanos R, Delcher AL, Dew IM, Fasulo D, Flanigan MJ, Huson DH, Kravitz SA, Miller JR, Mobarry CM, Reinert K, Remington KA, Zhang Q, Zheng XH, Nusskern DR, Lai Z, Lei Y, Zhong W, Yao A, Guan P, Ji RR, Gu Z, Wang ZY, Zhong F, Xiao C, Chiang CC, Yandell M, Wortman JR, Amanatides PG, Hladun SL, Pratts EC, Johnson JE, Dodson KL, Woodford KJ, Evans CA, Gropman B, Rusch DB, Venter E, Wang M, Smith TJ, Houck JT, Tompkins DE, Haynes C, Jacob D, Chin SH, Allen DR, Dahlke CE, Sanders R, Li K, Liu X, Levitsky AA, Majoros WH, Chen Q, Xia AC, Lopez JR, Donnelly MT, Newman MH, Glodek A, Kraft CL, Nodell M, Ali F, An HJ, Baldwin-Pitts D, Beeson KY, Cai S, Carnes M, Carver A, Caulk PM, Center $\mathrm{A}$, Chen $\mathrm{YH}$, Cheng ML, Coyne MD, Crowder M, Danaher S, Davenport LB, Desilets R, Dietz SM, Doup L, Dullaghan P, Ferriera S, Fosler CR, Gire HC, Gluecksmann A, Gocayne JD, Gray J, Hart B, Haynes J, Hoover J, Howland T, Ibegwam C, Jalali M, Johns D, Kline L, Ma DS, MacCawley S, Magoon A, Mann F, May D, McIntosh TC, Mehta S, Moy L, Moy MC, Murphy BJ, Murphy SD, Nelson KA, Nuri Z, Parker KA, Prudhomme AC, Puri VN, Qureshi H, Raley JC, Reardon MS, Regier MA, Rogers YH, Romblad DL, Schutz J, Scott JL, Scott R, Sitter CD, Smallwood M, Sprague AC, Stewart E, Strong RV, Suh E, Sylvester K, Thomas R, Tint NN, Tsonis C, Wang G, Wang G, Williams MS, Williams SM, Windsor SM, Wolfe K, Wu MM, Zaveri J, Chaturvedi K, Gabrielian AE, Ke Z, Sun J, Subramanian G, Venter JC, Pfannkoch CM, Barnstead M, Stephenson LD: A comparison of wholegenome shotgun-derived mouse chromosome 16 and the human genome. Science 2002, 296:1661-1671.

4. Cunningham F, Rios D, Griffiths M, Smith J, Ning Z, Cox T, Flicek P, MarinGarcin P, Herrero J, Rogers J, Weyden L van der, Bradley A, Birney E, Adams DJ: TranscriptSNPView: a genome-wide catalog of mouse coding variation. Nat Genet 2006, 38:853.

5. STAR Consortium, Saar K, Beck A, Bihoreau MT, Birney E, Brocklebank D, Chen Y, Cuppen E, Demonchy S, Dopazo J, Flicek P, Foglio M, Fujiyama A, Gut IG, Gauguier D, Guigo R, Guryev V, Heinig M, Hummel O, Jahn N, Klages S, Kren V, Kube M, Kuhl H, Kuramoto T, Kuroki Y, Lechner D, Lee YA, Lopez-Bigas N, Lathrop GM, Mashimo T, Medina I, Mott R, Patone G, Perrier-Cornet JA, Platzer M, Pravenec M, Reinhardt R, Sakaki Y, Schilhabel M, Schulz H, Serikawa T, Shikhagaie M, Tatsumoto S, Taudien S, Toyoda A, Voigt B, Zelenika D, Zimdahl H, Hubner N: SNP and haplotype mapping for genetic analysis in the rat. Nat Genet 2008, 40:560-566.

6. Sherry ST, Ward MH, Kholodov M, Baker J, Phan L, Smigielski EM, Sirotkin K: dbSNP: the NCBI database of genetic variation. Nucleic Acids Res 2001, 29:308-311.

7. Warren WC, Hillier LW, Marshall Graves JA, Birney E, Ponting CP, Grützner F, Belov K, Miller W, Clarke L, Chinwalla AT, Yang SP, Heger A, Locke DP, Miethke P, Waters PD, Veyrunes F, Fulton L, Fulton B, Graves T, Wallis J, Puente XS, López-Otín C, Ordóñez GR, Eichler EE, Chen L, Cheng Z, Deakin JE, Alsop A, Thompson K, Kirby P, Papenfuss AT, Wakefield MJ, Olender T, Lancet D, Huttley GA, Smit AF, Pask A, Temple-Smith P, Batzer MA, Walker $J A$, Konkel MK, Harris RS, Whittington CM, Wong ES, Gemmell NJ, Buschiazzo E, Vargas Jentzsch IM, Merkel A, Schmitz J, Zemann A, Churakov G, Kriegs JO, Brosius J, Murchison EP, Sachidanandam R, Smith C, Hannon GJ, Tsend-Ayush E, McMillan D, Attenborough R, Rens W, Ferguson-Smith M, Lefèvre CM, Sharp JA, Nicholas KR, Ray DA, Kube M, Reinhardt R, Pringle TH, Taylor J, Jones RC, Nixon B, Dacheux JL, Niwa H,
Sekita Y, Huang X, Stark A, Kheradpour P, Kellis M, Flicek P, Chen Y, Webber C, Hardison R, Nelson J, Hallsworth-Pepin K, Delehaunty K, Markovic C, Minx P, Feng Y, Kremitzki C, Mitreva M, Glasscock J, Wylie T, Wohldmann P, Thiru P, Nhan MN, Pohl CS, Smith SM, Hou S, Renfree MB, Mardis ER, Wilson RK: Genome analysis of the platypus reveals unique signatures of evolution. Nature 2008, 453:175-183.

8. Taillon-Miller P, Gu Z, Li Q, Hillier L, Kwok PY: Overlapping genomic sequences: a treasure trove of single-nucleotide polymorphisms. Genome Res 1998, 8:748-754.

9. Sachidanandam R, Weissman D, Schmidt SC, Kakol JM, Stein LD, Marth G, Sherry S, Mullikin JC, Mortimore BJ, Willey DL, Hunt SE, Cole CG, Coggill PC, Rice CM, Ning Z, Rogers J, Bentley DR, Kwok PY, Mardis ER, Yeh RT, Schultz B, Cook L, Davenport R, Dante M, Fulton L, Hillier L, Waterston RH, McPherson JD, Gilman B, Schaffner S, Van Etten WJ, Reich D, Higgins J, Daly MJ, Blumenstiel B, Baldwin J, Stange-Thomann N, Zody MC, Linton L, Lander ES, Altshuler D, International SNP Map Working Group: A map of human genome sequence variation containing 1.42 million single nucleotide polymorphisms. Nature 2001, 409:928-933.

10. Wong GK, Liu B, Wang J, Zhang Y, Yang X, Zhang Z, Meng Q, Zhou J, Li D, Zhang J, Ni P, Li S, Ran L, Li H, Zhang J, Li R, Li S, Zheng H, Lin W, Li G, Wang X, Zhao W, Li J, Ye C, Dai M, Ruan J, Zhou Y, Li Y, He X, Zhang Y, Wang J, Huang $X$, Tong W, Chen J, Ye J, Chen C, Wei N, Li G, Dong L, Lan F, Sun Y, Zhang Z, Yang Z, Yu Y, Huang Y, He D, Xi Y, Wei D, Qi Q, Li W, Shi J, Wang $M$, Xie F, Wang J, Zhang X, Wang P, Zhao Y, Li N, Yang N, Dong W, Hu S, Zeng C, Zheng W, Hao B, Hillier LW, Yang SP, Warren WC, Wilson RK, Brandström M, Ellegren $\mathrm{H}$, Crooijmans RP, Poel J van der, Bovenhuis $\mathrm{H}$, Groenen MA, Ovcharenko I, Gordon L, Stubbs L, Lucas S, Glavina T, Aerts A, Kaiser P, Rothwell L, Young JR, Rogers S, Walker BA, van Hateren A, Kaufman J, Bumstead N, Lamont SJ, Zhou H, Hocking PM, Morrice D, de Koning DJ, Law A, Bartley N, Burt DW, Hunt H, Cheng HH, Gunnarsson U, Wahlberg P, Andersson L, Kindlund E, Tammi MT, Andersson B, Webber C, Ponting CP, Overton IM, Boardman PE, Tang H, Hubbard SJ, Wilson SA, Yu J, Wang J, Yang H, International Chicken Polymorphism Map Consortium: A genetic variation map for chicken with 2.8 million single-nucleotide polymorphisms. Nature 2004, 432:717-722.

11. Hubbard TJ, Aken BL, Ayling S, Ballester B, Beal K, Bragin E, Brent S, Chen Y, Clapham P, Clarke L, Coates G, Fairley S, Fitzgerald S, Fernandez-Banet J, Gordon L, Graf S, Haider S, Hammond M, Holland R, Howe K, Jenkinson A, Johnson N, Kahari A, Keefe D, Keenan S, Kinsella R, Kokocinski F, Kulesha E, Lawson D, Longden I, Megy K, Meidl P, Overduin B, Parker A, Pritchard B, Rios D, Schuster M, Slater G, Smedley D, Spooner W, Spudich G, Trevanion S, Vilella A, Vogel J, White S, Wilder S, Zadissa A, Birney E, Cunningham F, Curwen V, Durbin R, Fernandez-Suarez XM, Herrero J, Kasprzyk A, Proctor G, Smith J, Searle S, Flicek P: Ensembl 2009. Nucleic Acids Res 2009, 37:D690-D697.

12. Kuhn RM, Karolchik D, Zweig AS, Wang T, Smith KE, Rosenbloom KR, Rhead B, Raney BJ, Pohl A, Pheasant M, Meyer L, Hsu F, Hinrichs AS, Harte RA, Giardine B, Fujita P, Diekhans M, Dreszer T, Clawson H, Barber GP, Haussler D, Kent WJ: The UCSC Genome Browser Database: update 2009. Nucleic Acids Res 2009, 37:D755-D761.

13. Thomas DJ, Trumbower H, Kern AD, Rhead BL, Kuhn RM, Haussler D, Kent WJ: Variation resources at UC Santa Cruz. Nucleic Acids Res 2007, 35:D716-D720.

14. Sayers EW, Barrett T, Benson DA, Bryant SH, Canese K, Chetvernin V, Church DM, DiCuccio M, Edgar R, Federhen S, Feolo M, Geer LY, Helmberg W, Kapustin Y, Landsman D, Lipman DJ, Madden TL, Maglott DR, Miller V, Mizrachi I, Ostell J, Pruitt KD, Schuler GD, Sequeira E, Sherry ST, Shumway M, Sirotkin K, Souvorov A, Starchenko G, Tatusova TA, Wagner L, Yaschenko $E$, Ye J: Database resources of the National Center for Biotechnology Information. Nucleic Acids Res 2009, 37:D5-15.

15. Stalker J, Gibbins B, Meidl P, Smith J, Spooner W, Hotz HR, Cox AV: The Ensembl Web site: mechanics of a genome browser. Genome Res 2004, 14:951-955.

16. Stabenau A, McVicker G, Melsopp C, Proctor G, Clamp M, Birney E: The Ensembl core software libraries. Genome Res 2004, 14:929-933.

17. Smedley D, Haider S, Ballester B, Holland R, London D, Thorisson G, Kasprzyk A: BioMart--biological queries made easy. BMC Genomics 2009, 10:22.

18. Kersey PJ, Lawson D, Birney E, Derwent PS, Haimel M, Herrero J, Keenan S, Kerhornou A, Koscielny G, Kähäri A, Kinsella RJ, Kulesha E, Maheswari U, Megy K, Nuhn M, Proctor G, Staines D, Valentin F, Vilella AJ, Yates A: 
Ensembl Genomes: extending Ensembl across the taxonomic space. Nucleic Acids Res 2010, 38:D563-D569.

19. Hubbard TJ, Aken BL, Beal K, Ballester B, Caccamo M, Chen Y, Clarke L, Coates G, Cunningham F, Cutts T, Down T, Dyer SC, Fitzgerald S, Fernandez-Banet J, Graf S, Haider S, Hammond M, Herrero J, Holland R, Howe K, Johnson N, Kahari A, Keefe D, Kokocinski F, Kulesha E, Lawson D, Longden I, Melsopp C, Megy K, Meidl P, Ouverdin B, Parker A, Prlic A, Rice S, Rios D, Schuster M, Sealy I, Severin J, Slater G, Smedley D, Spudich G, Trevanion S, Vilella A, Vogel J, White S, Wood M, Cox T, Curwen V, Durbin R, Fernandez-Suarez XM, Flicek P, Kasprzyk A, Proctor G, Searle S, Smith J, Ureta-Vidal A, Birney E: Ensembl 2007. Nucleic Acids Res 2007, 35:D610-D617.

20. Flicek P, Aken BL, Beal K, Ballester B, Caccamo M, Chen Y, Clarke L, Coates G, Cunningham F, Cutts T, Down T, Dyer SC, Eyre T, Fitzgerald S, Fernandez-Banet J, Gräf S, Haider S, Hammond M, Holland R, Howe KL, Howe K, Johnson N, Jenkinson A, Kähäri A, Keefe D, Kokocinski F, Kulesha E, Lawson D, Longden I, Megy K, Meidl P, Overduin B, Parker A, Pritchard B, Prlic A, Rice S, Rios D, Schuster M, Sealy I, Slater G, Smedley D, Spudich G, Trevanion S, Vilella AJ, Vogel J, White S, Wood M, Birney E, Cox T, Curwen V, Durbin R, Fernandez-Suarez XM, Herrero J, Hubbard TJ, Kasprzyk A, Proctor G, Smith J, Ureta-Vidal A, Searle S: Ensembl 2008. Nucleic Acids Res 2008, 36:D707-D714.

21. Cochrane G, Akhtar R, Aldebert P, Althorpe N, Baldwin A, Bates K, Bhattacharyya S, Bonfield J, Bower L, Browne P, Castro M, Cox T, Demiralp F, Eberhardt R, Faruque N, Hoad G, Jang M, Kulikova T, Labarga A, Leinonen R, Leonard S, Lin Q, Lopez R, Lorenc D, McWilliam H, Mukherjee G, Nardone F, Plaister S, Robinson S, Sobhany S, Vaughan R, Wu D, Zhu W, Apweiler R, Hubbard T, Birney E: Priorities for nucleotide trace, sequence and annotation data capture at the Ensembl Trace Archive and the EMBL Nucleotide Sequence Database. Nucleic Acids Res 2008, 36:D5-12.

22. DGAa [http://www.ebi.ac.uk/dgva]

23. Rios D, McLaren WM, Chen Y, Birney E, Stabenau A, Flicek P, Cunningham F: A database and API for variation, dense genotyping and resequencing data. BMC Bioinformatics 2010, 11:238

24. Ning Z, Cox AJ, Mullikin JC: SSAHA: a fast search method for large DNA databases. Genome Res 2001, 11:1725-1729.

25. International HapMap Consortium: A haplotype map of the human genome. Nature 2005, 437:1299-1320

26. Hinds DA, Stuve LL, Nilsen GB, Halperin E, Eskin E, Ballinger DG, Frazer KA, Cox DR: Whole-genome patterns of common DNA variation in three human populations. Science 2005, 307:1072-1079.

27. Fredman D, Siegfried M, Yuan YP, Bork P, Lehväslaiho $H$, Brookes AJ: HGVbase: a human sequence variation database emphasizing data quality and a broad spectrum of data sources. Nucleic Acids Res 2002, 30:387-391.

28. The European Genome-phenome Archive [http://www.ebi.ac.uk/ega

29. Hindorff LA, Sethupathy P, Junkins HA, Ramos EM, Mehta JP, Collins FS, Manolio TA: Potential etiologic and functional implications of genomewide association loci for human diseases and traits. Proc Natl Acad Sci USA 2009, 106:9362-9367.

30. Altshuler D, Pollara VJ, Cowles CR, Van Etten WJ, Baldwin J, Linton L, Lander ES: An SNP map of the human genome generated by reduced representation shotgun sequencing. Nature 2000, 407:513-516.

31. Harrison P, Pointon JJ, Farrar C, Brown MA, Wordsworth BP: Effects of PTPN22 C1858T polymorphism on susceptibility and clinical characteristics of British Caucasian rheumatoid arthritis patients. Rheumatology (Oxford) 2006, 45:1009-1011.

32. Barrett JC, Fry B, Maller J, Daly MJ: Haploview: analysis and visualization of LD and haplotype maps. Bioinformatics 2005, 21:263-265.

33. Paten B, Herrero J, Beal K, Fitzgerald S, Birney E: Enredo and Pecan: Genome-wide mammalian consistency-based multiple alignment with paralogs. Genome Res 2008, 18:1814-1828.

34. Paten B, Herrero J, Fitzgerald S, Beal K, Flicek P, Holmes I, Birney E: Genome-wide nucleotide-level mammalian ancestor reconstruction. Genome Res 2008, 18:1829-1843.

35. lafrate AJ, Feuk L, Rivera MN, Listewnik ML, Donahoe PK, Qi Y, Scherer SW, Lee C: Detection of large-scale variation in the human genome. Nat Genet 2004, 36:949-951.

36. Dalgleish R, Flicek P, Cunningham F, Astashyn A, Tully RE, Proctor $G$, Chen Y, McLaren WM, Larsson P, Vaughan BW, Beroud C, Dobson G, Lehvaslaiho H, Taschner PEM, den Dunnen PT, Devereau A, Birney E, Brookes AJ, Maglott DR: Locus Reference Genomic sequences: an improved basis for describing human DNA variants. Genome Medcine 2010, 2:24 [http://www.lrg-sequence.org].

doi: $10.1186 / 1471-2164-11-293$

Cite this article as: Chen et al., Ensembl variation resources BMC Genomics 2010, 11:293

\section{Submit your next manuscript to BioMed Central and take full advantage of:}

- Convenient online submission

- Thorough peer review

- No space constraints or color figure charges

- Immediate publication on acceptance

- Inclusion in PubMed, CAS, Scopus and Google Scholar

- Research which is freely available for redistribution

Submit your manuscript at www.biomedcentral.com/submit
C Biomed Central 